\title{
BIOCONTROL POTENTIAL OF TRICHODERMA SPP. AGAINST FUSARIUM OXYSPORUM IN SOLANUM LYCOPERSICUM L.
}

\author{
PAVITHRA RAMASAMY, LALITHA SUNDARAM* \\ Department of Botany, School of Life Sciences, Periyar University, Salem, Tamil Nadu, India. Email: pavirambot@gmail.com
}

Received: 12 March 2020, Revised and Accepted: 24 March 2020

\begin{abstract}
Objective: The main objective of this study was to determine the effect of biocontrol Trichoderma species agent against Fusarium oxysporum in Solanum lycopersicum L.

Methods: Genus Trichoderma effective biocontrol agent against fungal, bacterial pathogen. The fungal isolates Trichoderma viride (Tr01), Trichoderma harzianum (Tr02), and F. oxysporum (Fu04) were also identified through morphological characterization observed under a light microscope $(10 \mathrm{x} \times 40 \mathrm{x})$. The isolates ( $\mathrm{Tr} 01, \mathrm{Tr} 02$, Fu04) were confirmed through genetic DNA isolation and polymerase chain reaction analysis. After that pot culture study was conducted to test the antagonistic potential (Tr01, Tr02) and against (Fu04). Seeds of tomato (S. lycopersicum L.) were used in this experiment; treatment such as control, Tr01, Tr02, Fu04, Tr01+ Fu04, and Tr02+ Fu04 was given to the seeds sown in pots and maintained in appropriate distances.
\end{abstract}

Results: In pot culture after $45^{\text {th }}$ day after inoculation of bioinoculated plant (Tr02), significantly enhances plant length, fresh weight, dry weight, chlorophyll content, nitrogen content, NPK content, and soil microbial population.

Conclusion: In this experiment, Trichoderma spp. to control plant pathogen and improve yield and quality of crop. Fungal species belonging to the genus Trichoderma act as a biological agent. Bioinoculated plant (Tr02) significantly enhances plant growth ability to with stand under nutrient deficient conditions.

Keywords: Antagonistic effects, Chlorophyll, NPK content Trichoderma harzianum, Fusarium oxysporum, Trichoderma asperellum.

(C) 2020 The Authors. Published by Innovare Academic Sciences Pvt Ltd. This is an open access article under the CC BY license (http://creativecommons. org/licenses/by/4. 0/) DOI: http://dx.doi.org/10.22159/ajpcr.2020.v13i5.37108

\section{INTRODUCTION}

Soil microorganisms are usually present in numerous numbers near plant roots, where more content of organic compounds liberated by the root. The quality of root exudates can enhance the differential recruitment of microorganisms available in the soil [1]. The genus of the fungus Trichoderma spp. isolated from soil and agricultural waste and it performs interactions with and causes hyper parasitism in other fungi [2].

Soil-borne pathogens attack a wide range of susceptible plants and cause telluric diseases such as seed decay, damping-off, root rot, and blights [3]. Trichoderma spp. are abundant in soil and involves a different kind of interaction with other microorganisms in the rhizospheric. Some Trichoderma spp. are opportunistic and show parasitic lifestyle against other soil-borne fungi what makes them interesting mycoparasitic fungi for the biocontrol of soil-borne pathogens. Therefore, many researches in the literature recognized tremendous antagonistic profiles of different Trichoderma spp. against soil-borne pathogens. These Trichoderma are used as biological control agents against fungal phytopathogens [4]. Tomato (Solanum lycopersicum L.) is one of the most popular and nutritive vegetable crop grown all over the world. Tomato belongs to the family Solanaceae. It is an important nursery-based vegetable crop cultivated for its fleshy fruits. This fruit can be eaten raw or cooked. Tomato is known as productive as well as protective food. In large quantities, tomato is used to produce soup, juice, ketchup, puree, paste, and powder. It is a good source of Vitamin $\mathrm{A}$ and $\mathrm{C}, \beta$-carotene pigment, and also contains minerals such as iron and phosphorus [5]. Tomato plant is attacked by various diseases that significantly affect its growth and yield. Of which Fusarium wilt is one of the most serious diseases affecting its yield. This disease is caused by Fusarium oxysporum, Fusarium lycopersici (Sacc), and the yield loss due to this disease [6]. F. oxysporum is a soil-borne fungal pathogen that infects plants through roots at all stages of plant growth, causes major economic losses by inducing necrosis, and wilting symptoms in many crop plants. Fusarium wilt of tomato caused by F. oxysporum, F. lycopersici is the major limiting factor in the production of tomato. The disease causes great losses, especially on the susceptible varieties of tomato, especially when soil and air temperature are rather high during the warm seasons [7].

In the present study, to determine the effect of biocontro agent Trichoderma spp. against plant pathogenic fungi $F$. oxysporum.

\section{METHODS}

\section{Isolation and identification of the isolates}

The soil samples were collected from agriculture land soil in Salem District, Tamil Nadu, India. The bioagents were isolated from the representative sample by following the serial dilution plate technique [8]. Trichoderma isolate characterized by a rapid growth rate in culture and by the production of numerous spores (conidia) with varying shades of green, microscopically observe for colony growth rate, colony color, reverse color, colony edge, mycelial form, conidiophore branching, conidial color were selected and microscopic observation available in literature [9].

\section{Isolation and identification of pathogen}

The infected tomato leaf tissue of the collar region of the plant was collected and repeatedly washed in freshwater and surface was sterilized by three times washing in distilled water. Then, the species of infected tissue were placed on potato dextrose agar (PDA) medium was inoculated at $22 \pm 2^{\circ} \mathrm{C}$ 7 days. After incubation, white mycelia formed the pathogen was purified and multiplied subsequently through hyphal tip culture on PDA, for 
preparation of inoculums. F. oxysporum just based on colony appearance and morphological characteristics of $F$. oxysporum produced white to pale violet or pink pigmentation for naked eyes and microscopically.

\section{Antagonistic activity}

Antagonistic effect of Trichoderma isolates was evaluated against soil born pathogenic fungi by dual culture method [10]

\section{DNA isolation and 16s rRNA amplification}

The selected culture was inoculated into $50 \mathrm{ml}$ of culture medium and incubated until it reached $600 \mathrm{~nm}$. The DNA isolation and 16s rRNA amplification process [11].
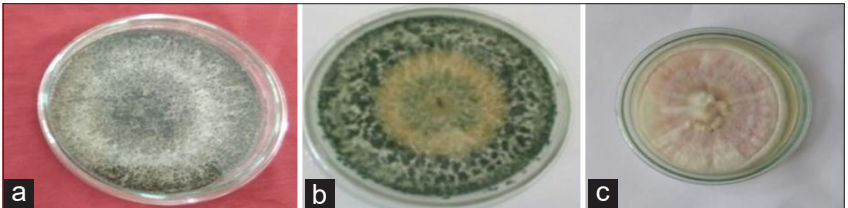

Fig. 1: Morphological observation of Trichoderma spp. and Fusarium oxysporum (a) Trichoderma harzianum,

(b) Trichoderma viride, (c) Fusarium oxysporum

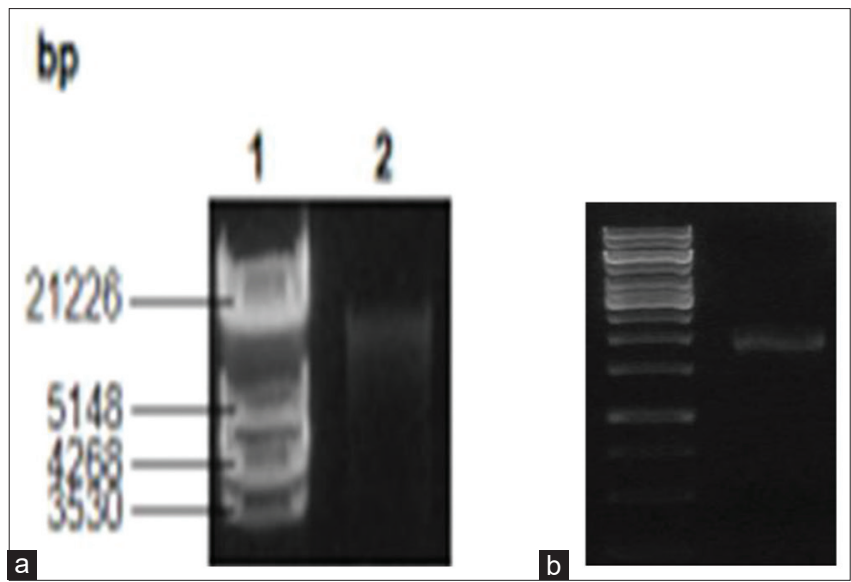

Fig. 2: Polymerase chain reaction analysis (a) Trichoderma harzianum and (b) Trichoderma viride (1 Kb) 16s rRNA amplification
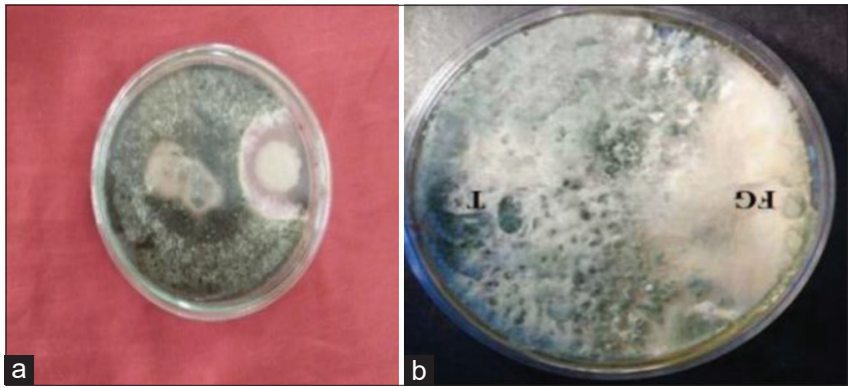

Fig. 3: Antagonistic activity of Trichoderma spp. against Fusarium oxysporum (a) Trichoderma harzianum, (b) Trichoderma asperellum
Polymerase chain reaction (PCR) program

The PCR program was followed by the following steps

$\begin{array}{ll}\text { Steps } & \text { Action timing } \\ \text { Initial denaturation } & 94^{\circ} \mathrm{C} 5 \mathrm{~min} \\ \text { Denaturation } & 94^{\circ} \mathrm{C} 1 \mathrm{~min} \\ \text { Annealing } & 55^{\circ} \mathrm{C} 1 \mathrm{~min} \\ \text { Extension } & 74^{\circ} \mathrm{C} 90 \mathrm{~s} \\ \text { Final extension } & 72^{\circ} \mathrm{C} 8 \mathrm{~min} \\ \text { Repeat step } 2-4 \text { for } 35 \text { cycles }\end{array}$

Repeat step 2-4 for 35 cycles.

Sequencing was carried out with the same universal primers on $\mathrm{ABI}$ 3100 automated DNA sequence by standard BigDye ${ }^{\circledR}$ Terminator v3.1 Cycle Sequencing Kit (Life Technologies, USA) cyclic amplification method at Progen Scientific Lab in Salem.

\section{Assay for extracellular enzyme activity}

$\beta$-1,3-glucanase activity

For assay of $\beta$-1,3-glucanase enzyme, $0.5 \mathrm{ml}$ laminar in, $1.0 \mathrm{ml}$ of $0.05 \mathrm{M}$ citrate buffer $(\mathrm{pH} 4.8)$, and $0.5 \mathrm{ml}$ culture filtrate were mixed and incubated at $40^{\circ} \mathrm{C}$ for $60 \mathrm{~min}$. An equal volume of dinitrosalicylic acid reagent was added to the reaction mixture and warmed in boiling water for 15 min. The absorbance of the reaction mixture was measured at $575 \mathrm{~nm}$ in a spectrophotometer and compared with a standard graph drawn by following the same procedure but using different concentrations of glucose instead of culture filtrate. The quantity of reducing sugar was calculated from the glucose standards used in the assay and activity of $\beta$-1,3-glucanase was expressed in ml. One corresponds to the release of 1 mol glucose equivalent per second [12].

\section{Chitinase activity}

A mixture of $0.5 \mathrm{ml}$ culture filtrate, $0.5 \mathrm{ml}$ suspension of colloidal chitin, and $1.0 \mathrm{ml}$ of McIlvaine buffer ( $\mathrm{pH} 4.0$ ) were mixed and incubated at $37^{\circ} \mathrm{C}$ for $2 \mathrm{~h}$ in a water bath with constant shaking. The reaction was stopped by boiling $3 \mathrm{~min}$ in a heated water bath. Three-milliliter potassium ferricyanide reagent was added and warmed in boiling water for $15 \mathrm{~min}$. The amount of $\mathrm{N}$-acetyl glucosamine released was estimated following the methods [12]. The absorbance of the reaction mixture was measured in a spectrophotometer at $420 \mathrm{~nm}$. The amount of reducing sugar released was calculated from standard curves and chitinase enzyme activity was expressed in (pmol/s) per milliliter.

Collection and seed selection of seeds

The seed of tomato (Solanum lycoprescum L.) variety PKM-2 was collected from agricultural office (seelanayakanpatty) in Salem. The seeds were surface-sterilized with $0.5 \%$ sodium hypochlorite for $3 \mathrm{~min}$ followed by repeated washing in distilled water.

\section{Experimental design}

The experiment designed with the following combinations control, Trichoderma (Tr01), Fusarium (Fs04), Tr01 + Fs04, control, Trichoderma (Tr02) Fusarium (Fs04), and Tr02 + Fu04. The pots were maintained appropriate distances. Water was supplied after intervals of $24-48 \mathrm{~h}$ as required. The plant samples collected at 45 day after inoculation (DAI) from pot culture were subjected to analyses.

\section{Growth characteristics of plant}

Plants were harvested at 45 DAI and separated into leaves, shoot, and roots. They plant shoot, root length $(\mathrm{cm})$, plant fresh, dry weight $(\mathrm{g})$,

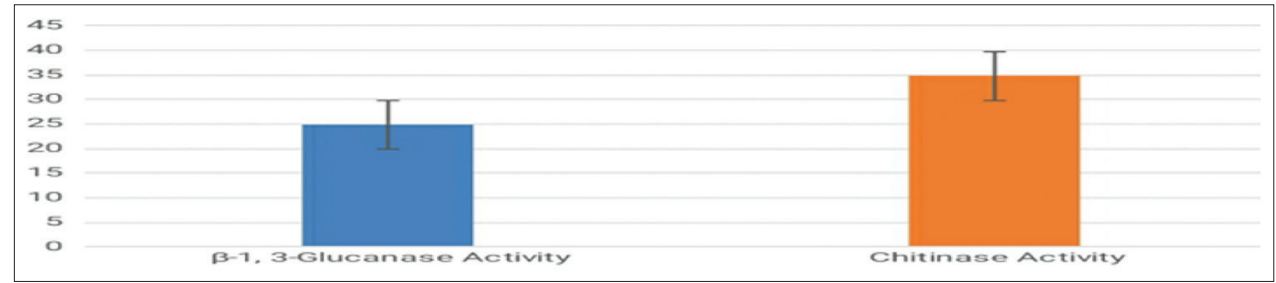

Fig. 4: Enzyme activity of chitinase and $\beta$-1,3-glucanase activity 
and chlorophyll content were calculated in bioinoculants treated plants and non-inoculants plants. Three plants were taken each for to measure the mean value for all the treated and control plants.

\section{Extraction}

Two hundred mg of fresh young leaves were ground with $10 \mathrm{ml}$ of $18 \%$ acetone pestle mortar and spun at $2500 \mathrm{~g}$ for $10 \mathrm{~min}$ at $200^{\circ} \mathrm{C}$ in centrifuge. The homogenate was re-extracted with $80 \%$ acetone until the green color was disappear in the residue and the extract was pooled and made up of $20 \mathrm{ml}$ with $80 \%$ acetone.
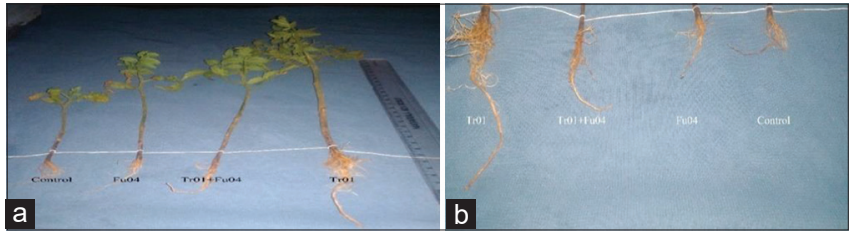

Fig. 5: Tr01 - Growth characteristic of (Solanum lycopersicum L.) with bioinoculants inoculated pots at $\mathbf{4 5}$ day after inoculation

(a) shoot length (b) root length
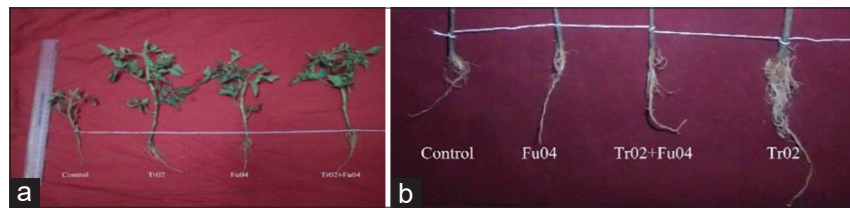

Fig. 6: Tr02 - Growth characters of (Solanum lycopersicum L.) with bioinoculants inoculated pots at 45 day after inoculation (a) shoot length (b) root length
Estimation of chlorophyll content

Estimation of chlorophyll a, b and total chlorophyll content followed by Arnon [13] method.

\section{Soil nitrogen content}

The soil nitrogen content was estimated by Subbiah and Asija [14] method. Soil phosphorus was estimated by the method by the given by Olsen et al. [15]. The potassium content of the soil was estimated by the method of Jackson [16]

\section{Soil microbial population}

Microbial population in the soil sample was determined by the dilution plate's techniques. The soil sample (1 g) was serially diluted water to get $10^{-3}$ dilutions. An aliquot of the sample was plated either in nutrient agar medium for total bacteria population or potato dextrose and Rose Bengal Agar medium for the total fungal population. After 2-5 days of incubation at $30^{\circ} \mathrm{C}$, the plates were observed for colony formation. The total number of colonies in each pate was scored. The results were expressed as colony-forming unit per gram soil.

\section{RESULTS}

Isolation of soil microbes

Fungal was isolated from different agricultural filed. Soil sample collected from Alagapuram, Bharathi Nagar Salem District. Serially diluted samples were placed on PDA medium colony that produced on the light green and dark green in color. The sample was named as (Tr01, Tr02) maintained in PDA medium. Fungal isolates were carried out using morphological characterization as observed, the result was depicted in Fig. 1.

\section{Identification of fungal isolates}

The fungal isolates were carried out using the morphological characterization of (Tr01) light green colony, chlamydospores, and

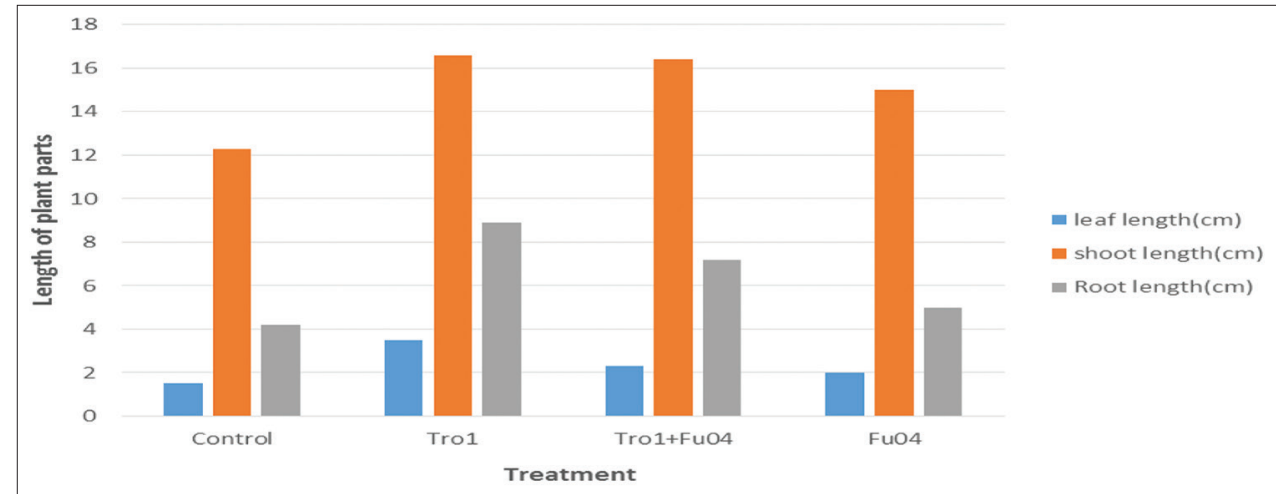

Fig. 7: Tr0I - Growth characters of Solanum lycopersicum L. - leaf, shoot, and root length

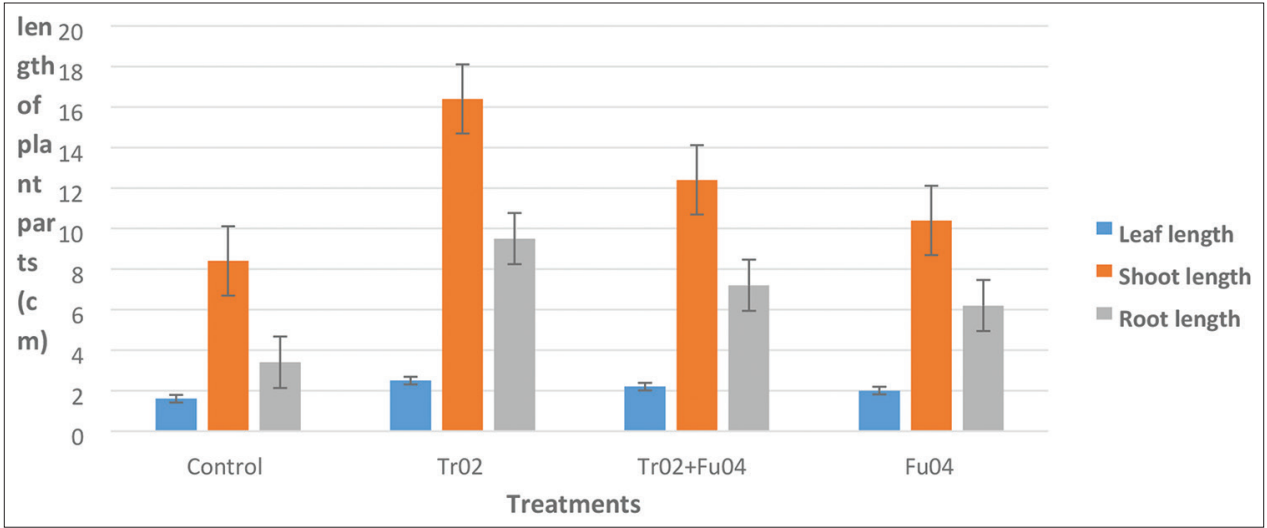

Fig. 8: Tro2 - Growth characters of Solanum lycopersicum L. Leaf, shoot, and root, length at 45 day after inoculation (cm/plant) 
conidiophores. (Tr02) morphological characterization of dark green colony color, conidial shape observed under a light microscope $(10 x \times 40 x)$, and the result were depicted in Fig. 2 .

\section{Isolation and identification of plant pathogen}

Microbes isolated from infected plant samples for wilt, leaf spot, and blight of tomato. A specific fungus was successfully isolated from tomato leaf. The infected plant sample pure cultured on PDA medium, identified through morphological characterization of $F$. oxysporum produced white color or pink color pigmentation, for naked eyes. Observe under the light microscope $(10 \mathrm{x} \times 40 \mathrm{x})$ and the result was defected in Fig. 1.

\section{Antagonistic activity}

Trichoderma isolation was screened for their antagonistic potential against fungal pathogens using dual culture technique. Trichoderma species were screened for antifungal activity against Fusarium spp. and zone of inhabitation was taken as an indicator of antifungal property in the dual culture method (Fig. 3).

\section{PCR analysis}

The microbial isolates ( $\operatorname{Tr} 01, \operatorname{Tr} 02)$ were confirmed through genetic DNA isolation and PCR analysis (Fig. 2)

\section{Extracellular enzyme activity of Trichoderma spp.}

The two isolates showed significantly higher chitinase and $\beta-1,3$ glucanase activities with the supplement of different carbon sources as substrates in the basal media. The highest chitinase enzyme activity was recorded with Tro1 (34. 88) compared with $\beta$-1-3-glucanase enzyme activity was recorded with (24.93). The production of chitinase and $\beta$-1,3-glucanase is summarized in Fig. 4.

\section{Pot culture study}

The result obtained from the study on the effect of two different treatments, control, Trichoderma (Tr01), Fusarium (Fu04), Tr01 + Fu04, control, Trichoderma (Tr02), Fusarium (Fu04), and Tr02 + Fu04 management of tomato seedling.

Determination of plant length in $(\mathbf{c m})$

After 45 days of inoculation, the Tr01 and Tr02 inhibited the Fu04 (F. oxysporum) and also increased $S$. lycopersicum growth parameters.

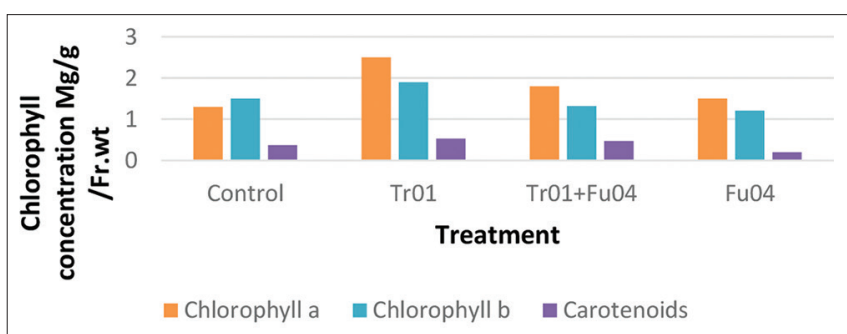

Fig. 9: Tr01 - Analysis of chlorophyll a, b, and carotenoids content in Solanum lycopersicum L. at 45 day after inoculation (mg/g/fr.wt)
Plant height was measured in three plants per pot. Each replicate was calculated in (cm) using a ruler. Biocontrol agents Tr01 inoculated plant growth $(31 \mathrm{~cm})$, Tr02 inoculated plant growth parameter $(16.3 \mathrm{~cm})$ and when compared to that of control $(18 \mathrm{~cm})$ and Fu04 $(14.9 \mathrm{~cm})$ plants (Figs. 5-8).

\section{Determination of chlorophyll (mg/gf, Wt)}

The chlorophyll a, b, and carotenoids content ultimately affected and its accumulation was significantly reduced to compare with control. The result showed that there was high chlorophyll accumulation in control, Tr01, and Tr02 treated pots. Similarly, biocontrol agents Tr01 and Tr02 inoculated plants chlorophyll a, b, and carotenoids contents. Bioinoculants were highest enhancing the plant chlorophyll content. It was evident Tr02 that showed better results for chlorophyll content (Figs. 9 and 10).

\section{Fresh weight of plants and dry weight of plant (g)}

The measurement was taken after 45 DAI. They were compared to be bioinoculated plants and control. Leaf, stem, and root fresh weight was measured in three plants per pot. Similarly, bio inoculant agents Tr01 inoculated plant fresh weight $(9 \mathrm{~g})$ when compared to that of control (1.7 g) and Fu04 (1.4 g). Bioinoculants were highly enhanced the plant fresh weight. Tr02 inoculated plant fresh weight (13.4 g) when compared to that of control $(9 \mathrm{~g})$ and Fu04 (6 g). (Tr02) plant fresh weight (Figs. 7 and 8).

After recording, the fresh weight of plants placed inside of the hot air oven for continuous 3 days. After 3 days of incubation, the dry weight of plants was recorded and the data obtained were analysis. Similarly, bioinoculant control agents Tr01 inoculated plants dry weight (3.8 g) when compared to that of control (0.05 g) and Fu04 (2.4 g) plant pathogen was highly inhibited using bioinoculants. Bioinoculants were highly enhanced the plant dry weight. Bioinoculants control agents Tr02 inoculated plants dry weight $(7 \mathrm{~g}$ ) when compared to that of control (0.04 g) and Fu04 (1.5 g) plant pathogen was highly inhibited using bioinoculants. Tr02 was a highly enhanced plant dry weight (Figs. 8 and 11).

\section{Soil analysis}

Soil NPK content was more pronounced in dual inoculated soils and as well as in field trials. In inoculated soil had less NPK content and bioinoculants inoculated soil contain a high level of nutrients (Table 1).

\section{Soil microbial population}

Analysis of the microbial population in a soil sample from control and microbial inoculated plants sown in the pots. Count the microbial colonies in the naked eye. Respect to all the two parameters, namely, total bacterial population and fungal population was analyzed.

After the inoculation, the effects significantly higher in soil sample inoculation with bioinoculants for the entire soil sample studied, as compared with inoculated control. The soil had a fungal population of $12.6 \times 107 \mathrm{cfu} / \mathrm{g}$ soil and pathogen showed soil microbial population was $3.2 \times 107 \mathrm{cfu} / \mathrm{g}$ soil (Fig. 13).

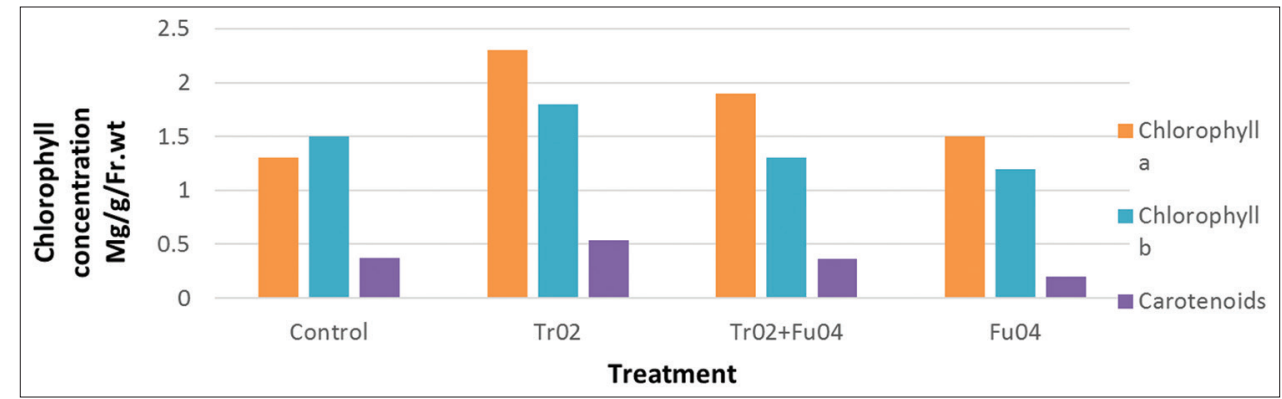

Fig. 10: Tr02 - Analysis of chlorophyll a, b, and carotenoids content in Solanum lycopersicum L. at 45 day after inoculation (mg/g/fr.wt) 


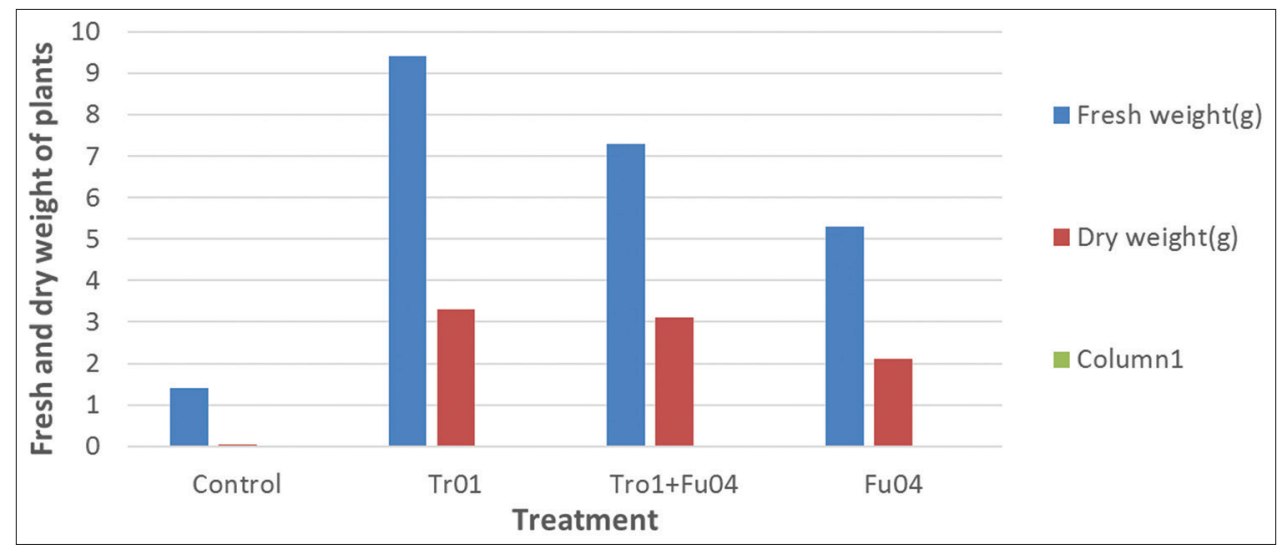

Fig. 11: Tro1 - Growth characters of Solanum lycopersicum L. - fresh weight and dry weight at 45 day after inoculation (g/plant)

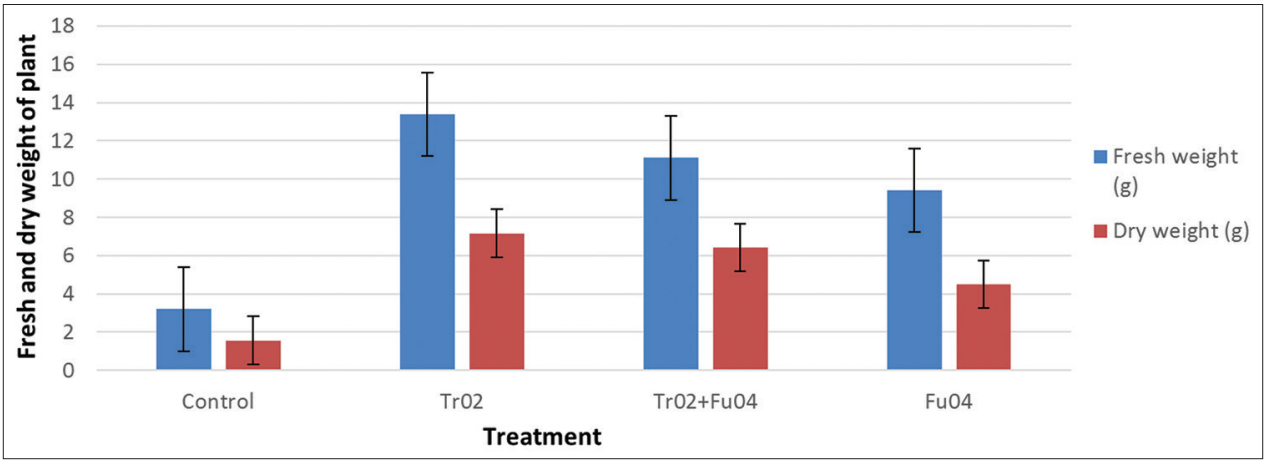

Fig. 12: Tr02 - growth characters of fresh weight and dry weight at 45 day after inoculation $(\mathrm{g} / \mathrm{plant})$

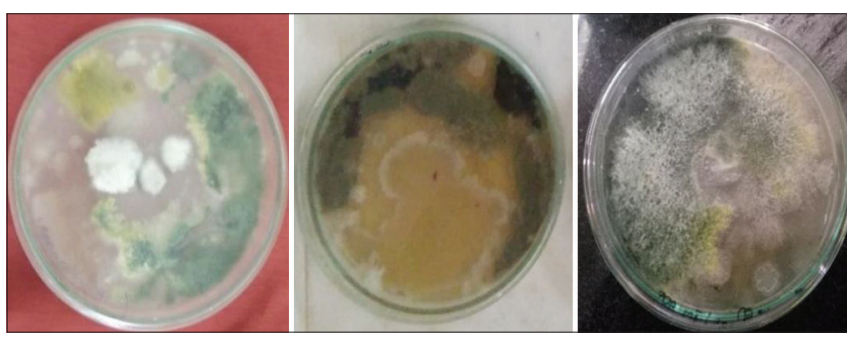

Fig. 13: Isolation of microbial population

Table 1: Effect of bioinoculants on total nitrogen content in Solanum lycopersicum L. at 45 DAI (mg N/g dry plant)

\begin{tabular}{lll}
\hline S. No. & Treatments & Total nitrogen content (mg N/g dry plant) \\
\hline 1 & Control & 1.08 \\
2. & Tr01 & 2.38 \\
3. & Tr01+Fu04 & 1.06 \\
4. & Fu04 & 0.96 \\
5. & Tr02 & 1.23 \\
6. & Tr02+Fu04 & 1.56 \\
\hline
\end{tabular}

DAI: Day after inoculation

\section{CONCLUSION}

In this experiment, Trichoderma ( $\operatorname{Tr} 01, \operatorname{Tr} 02)$ to control plant pathogen and improve yield and quality of crop. Fungal species belonging to the genus Trichoderma act as a biological agent. Bioinoculated plant (Tr02) significantly enhances plant biomass, chlorophyll content, nitrogen content, NPK content, and soil microbial population. Bioinoculant
(Tr02) highly inhibits plant pathogen (Fu04) and there was increase plant growth ability to with stand under nutrient-deficient conditions.

\section{AUTHORS' CONTRIBUTIONS}

The study was designed of the article, guidance, and feedback, and reviewing was done by Dr. S. Lalitha, Assistant Professor, Department of Botany, Periyar University, Salem, Tamil Nadu, India. R. Pavithra, Research Scholar, contributed to conducting experiments, collection of data, and preparation of the manuscript was also done by them.

\section{CONFLICTS OF INTEREST}

There are no conflicts of interest.

\section{AUTHORS' FUNDING}

The author(s) received no specific funding for this work.

\section{REFERENCES}

1. Wolfe BE, Klironomos JN. Breaking new ground: Soil communities and exotic plant invasion. BioScience 2005;55:477-87.

2. Monte E. Understanding Trichoderma: Between biotechnology and microbial ecology. Int Microbiol 2001;4:1-4.

3. Amraoui B, Biard J, Kbal F, El Wahidi M, Kandil M. Activity of haliscosamine against Fusarium oxysporum F. sp. Melonis: In vitro and in vivo analysis. Springerplus 2015;4:16.

4. Dighton J, White JF, Oudemans P. The Fungal Community; Its Organization and Role the Ecosystem. $3^{\text {rd }}$ ed. United Kingdom: Taylor \& Francis; 2005. p. 93-115.

5. Abdullah A, Ahmad S, Kamaluddeen R. Efficacy of Trichoderma spp, neem products and carbendazim against Fusarium wilt of tomato in pot condition. Int J Agric Sci Res 2013;3:73-80.

6. Dwivedi SK. Effectiveness of some antagonistic fungi and botanicals against Fusarium solani and Fusarium oxysporum infecting brinjal and 
tomato plants. Asian J Plant 2014;8:18-25.

7. Mallick A, Mitra A. Salicylic acid-induced resistance to Fusarium oxysporum in tomato. Plant Physiol Biochem 2009;8:18-25.

8. Ben-David A, Davidson E. Estimation method for serial dilution experiments. J Microbiol Methods 2014;107:214-21.

9. Oiveira AG, Chagas AF Jr., Santos GR, Miller LO, Chagas LF. Potential phosphate solubIlization and AIA production of Trichoderma spp. Green J Agroecol Sust Dev 2012;7:149-55.

10. Skidmore AM, Dickinson CM. Colony internations and hyphal interference between Saprophytic and phyllophance fungi. Transplant Br Mycol Soc 1976;66:57-64.

11. Sambrook J, Fritsch EF, Maniatis T. Molecular Cloning; A Laboratory
Manual. United States: Cold Spring Harbor Laboratory Press; 1989.

12. Ressing JL, Strominger JL, Leloir LF. A modified colorimetric method for estimation of N-acetylamine sugars. J Biol Chem 1955;217:959-66.

13. Arnon OI. Copper enzymes in isolated chloroplasts. 1. Polyphenol oxidase in Beta vulgaris. Plant 1949;24:1-15.

14. Subbiah BV, Asija GL. A rapid procedure for determination of available nitrogen in soil. Curr Sci 1956;25:259-60

15. Olsen SR, Cole CV, Watanabe FS, Dean LA. Estimation of available phosphorus. In: Soil Extraction With Sodium Bicarbonate. US: U. S. Department of Agriculture; 1954. p. 939.

16. Jackson ML. Soil Chemical Analysis. New Delhi: Prentice Hall of India Pvt. Ltd.; 1958. p. 498. 